\title{
A Transformerless Medium Voltage Multiphase Motor Drive System
}

\author{
Dan Wang ${ }^{1}$, Jiawei Yang ${ }^{2}$, Zhu Chen ${ }^{1}$, Chengxiong Mao ${ }^{1, *}$ and Jiming Lu ${ }^{1}$ \\ 1 School of Electrical and Electronic Engineering, Huazhong University of Science and Technology, \\ Wuhan 430074, China; wangdan@mail.hust.edu.cn (D.W.); allenbamboo@163.com (Z.C.); \\ lujiming@mail.hust.edu.cn (J.L.) \\ 2 Dongfang Electric Corporation, New \& Hi-tech Industry Western Zone, Xixin Avenue No. 18, \\ Chengdu 611731, China; yangjw02@dongfang.com \\ * Correspondence: cxmao@hust.edu.cn; Tel.: +86-27-8754-2669
}

Academic Editor: Jihong Wang

Received: 31 January 2016; Accepted: 18 April 2016; Published: 27 April 2016

\begin{abstract}
A multiphase motor has several major advantages, such as high reliability, fault tolerance, and high power density. It is a critical issue to develop a reliable and efficient multiphase motor drive system. In this paper, a transformerless voltage source converter-based drive system for a medium-voltage (MV) multiphase motor is proposed. This drive converter employs cascaded $\mathrm{H}$-bridge rectifiers loaded by $\mathrm{H}$-bridge inverters as the interface between the grid and multiphase motor. The cascaded H-bridge rectifier technique makes the drive system able to be directly connected to the MV grid without the phase-shifting transformer because it can offset the voltage level gap between the MV grid and the semiconductor devices, provide near-sinusoidal AC terminal voltages without filters, and draw sinusoidal line current from the grid. Based on a digital signal processor (DSP), a complete improved Phase Disposition Pulse Width Modulation (PD-PWM) method is developed to ensure the individual DC-link capacitor voltage balancing for enhancing the controllability and limiting the voltage and power stress on the H-bridge cells. A downscaled prototype is designed and developed based on a nine-phase motor. The experimental results verify the excellent performances of the proposed drive system and control strategy in steady-state and variant-frequency startup operations.
\end{abstract}

Keywords: cascaded H-bridge converter; motor drive; multiphase motor; PD-PWM; transformerless

\section{Introduction}

The origin of multiphase motor drives dates back to 1969 when a five-phase voltage source inverter-fed induction motor drive was proposed [1]. Until the 1990s, due to the technological advancements in semiconductor devices and as for the emerging development of high-power applications, such as electric ship propulsion, locomotive traction, electric and hybrid electric vehicles, and "more-electric" aircraft, it has witnessed a surge of research interest within the drives research community [1,2]. The primary utilization of a multiphase motor drive is restricted to specialized applications where a conventional three-phase drive does not meet the requirements. However, it possesses many other attractive features over their three-phase counterparts, such as higher efficiency, greater fault tolerance, smaller pulsating torques, increased power in the same frame, and so on [1-3]. Thus, many researchers have discussed the various issues related to the use of multiphase motor as an alternative to the three-phase motor [4-7].

The medium-voltage (MV) drives have found widespread applications in industry [8-11]. A general block diagram of the typical MV drives available on the market is introduced in [11]. All of them have the exact same feature; that the phase-shifting transformer with multiple secondary 
windings is usually used for the reduction of line current harmonics and isolation between the power source and the motor. With the goal of eliminating this heavy and costly phase-shifting transformer, some significant work has been done [12-19]. Reference [12] presents a hybrid cascaded H-bridge multilevel motor drive control scheme for electric/hybrid electric vehicles. A sensorless drive of a three-phase induction motor is introduced in [17]. In [18], a transformerless hybrid active filter is integrated into a conventional MV motor drive system to mitigate harmonic currents. A theoretical transformerless cascaded AC-DC-AC converter for multiphase propulsion drive is proposed in [19]. However, less attention was paid to the areas of the high efficiency and high performances of MV multiphase motor drives.

In this paper, a transformerless MV multiphase motor drive scheme is proposed based on the cascaded H-bridge converter technique. An improved PD-PWM method aiming at balancing DC-link capacitor voltages for the proposed drive system is presented. A downscale nine-phase motor drive system is designed and constructed. The experimental results verify the viability and effectiveness of the proposed motor drive system. This paper is presented as follows. (1) A brief introduction of the proposed transformerless motor drive is described in Section 2; (2) Section 3 states the overall control scheme of the system; (3) the principle and implementation of the improved PD-PWM for DC voltage balancing is discussed in Section 4; (4) the experimental results are represented in Section 5; (5) finally, conclusions and future extensions of this research are summarized in Section 6.

\section{System Configuration}

Figure 1 shows the proposed transformerless MV multiphase motor drive system configuration. The drive system consists of a static drive converter and a multiphase motor (e.g., $3 k$-phase motor). The static drive converter is a three-phase-input and multiphase-output two-stage voltage source converter (VSC). For the convenience of discussion, we still call the drive converter a three-phase system. The input terminals of the converter, in a Y-type configuration, are directly connected to the three-phase MV distribution systems. The output terminals of the drive converter are connected to the stator terminals of the multiphase motor. Herein, compared with the conventional MV drives, the line-side phase-shifting transformer is removed, which results in the reduction of space, weight, and cost requirements.

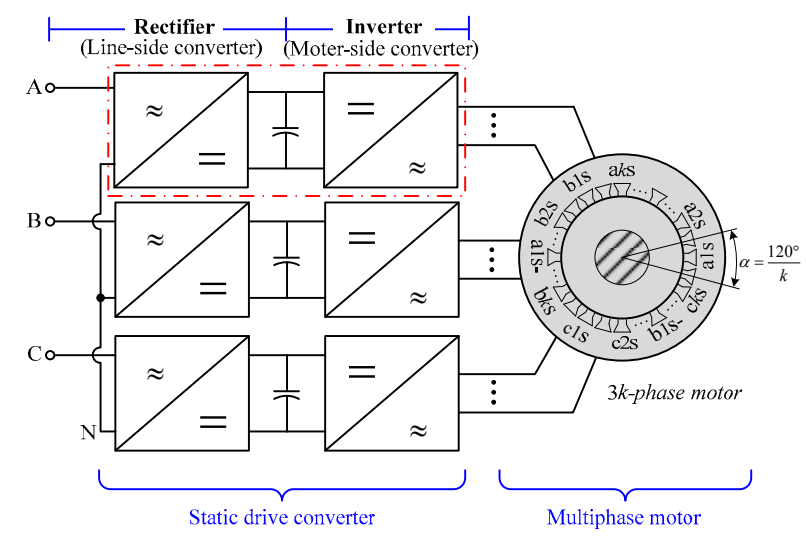

(a)

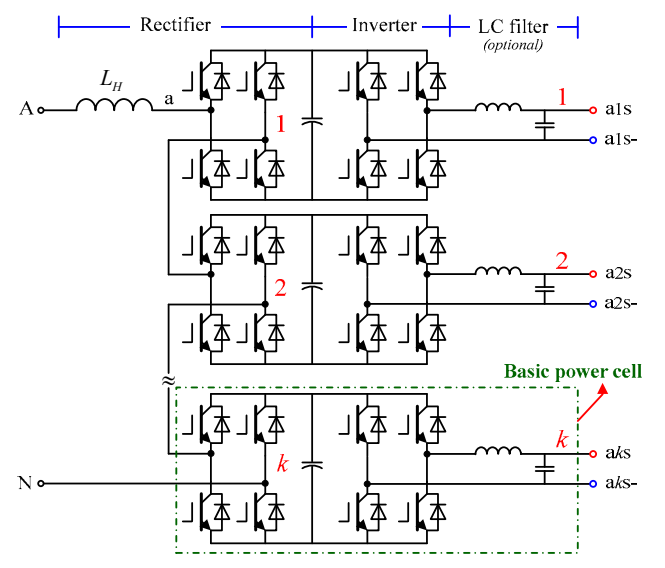

(b)

Figure 1. The proposed transformerless medium-voltage multiphase motor drive system. (a) Drive system; (b) The detailed configuration of the static converter (phase A).

Each phase of the drive converter consists of a line inductor $\left(L_{H}\right)$ and $k$ identical basic power cells of which inputs (line side) are connected in series to fabricate the phase-to-neutral voltage matched with the grid and outputs feed the related motor stator windings. Each power cell includes a front-end three-level (3L) H-bridge converter, a capacitive DC link, a back-end 3L H-bridge inverter, and 
an optional LC filter. As shown in Figure $1 b$, the $k$ front-end H-bridges are cascaded to interconnect with the power source (e.g., MV distribution systems), and the $k$ back-end H-bridges form $k$ independent single-phase outputs for feeding the multiphase motor. The cascaded H-bridges with the line inductor works as an active pulse-width modulation (PWM) rectifier. The cascaded H-bridge structure (known as cascaded multilevel converter) has attractive advantages in applications of the high-power MV and high-voltage (HV) drives with frequency modulation control [20]. In the proposed scheme, the cascaded multilevel converter technique makes semiconductor devices with voltage and current limitation can be used in the converter or inverter which is directly connected to the MV power grid without any isolation transformer. In addition, based on this structure, the power can bidirectionally flow between the grid and motor, which means that the energy of the motor will be fed back to the grid when the motor is in braking. Therefore, the brake circuit can be abandoned.

For the proposed drive system, the input high voltages are divided equally between the cascaded basic power cells and rectified to DC voltages. Then, the DC voltage in each basic power cell is inverted into AC voltage to power the corresponding winding of the multiphase motor.

Assuming the DC-link voltage to be $V_{\mathrm{dc}}$, each $\mathrm{H}$-bridge can fabricate three voltage levels, namely, $+V_{\mathrm{dc}}, 0$, and $-V_{\mathrm{dc}}$. Therefore, the rectifier with $k \mathrm{H}$-bridges in a cascade can produce $2 k$ +1 voltage levels per phase on the AC terminals. It more accurately portrays a sinusoidal waveform than a conventional single 3L H-bridge converter, which makes small AC-side filter requirements. Furthermore, this can guarantee to obtain high-quality AC waveforms at low device switching frequencies which can reduce switching losses.

The value of " $k$ " (number of basic power cells per phase) depends on the voltage level of the power source, the rated voltage of the semiconductor devices, and the number of the stator windings of the motor. It can be calculated by Equation (1) when taking insulated gate bipolar transistors (IGBTs) with voltage rating $V_{\mathrm{D}}$ as the power switches for the drive converter, assuming that the stator windings can always match the requirements.

$$
k=\left[\sqrt{\frac{2}{3}} \frac{\eta E}{V_{D}}\right]
$$

where $E$ is the rms value of the line-to-line voltage of the source, $\eta$ is voltage margin coefficient.

The maximum AC terminal voltage $U$ of a single power cell is:

$$
U=\sqrt{\frac{2}{3}} \frac{E}{m k}
$$

where $m$ is modulation index of the line-side $\mathrm{H}$-bridge converter. This voltage is also the maximum voltage that the motor-side $\mathrm{H}$-bridge inverter can fabricate.

For example, the supply voltages for motors of which power is upward of 200-kW are mostly $6 \mathrm{kV}$ and $10 \mathrm{kV}$ in China [21]. Correspondingly, the number of the basic power cells connected in series at the input side per phase may be not less than three and five if $3.3 \mathrm{kV}$ IGBTs are used. At the same time, the rated voltage of the stator windings of the multiphase motor can be set at about $1300 \mathrm{~V}$. Apparently, the proposed drive converter is a buck scheme. According to the actual input voltage levels and motor power ratings, the number of the power cells of each phase could be increased to reduce semiconductor device voltage stresses and power requirements.

Since the motor drive converter has $k$ outputs per phase, the number of the phases (stator windings) of the multiphase motor should be $3 k$ to achieve power balance between the high-voltage three-phase input side and the low-voltage multiphase output side. In other words, the proposed drive system is suitable for the triple stator winding multiphase motor.

If the concentrated winding technique is adopted, the equivalent mechanical angle of adjacent stator windings is:

$$
\alpha=\frac{360^{\circ}}{3 k}=\frac{120^{\circ}}{k}
$$


In addition, unlike conventional MV drive systems using the phase-shifting transformer providing electrical isolation, the proposed multiphase motor drive system achieves electrical isolation by its independent and isolated stator windings because the $3 k$ output voltages of the drive converter are not isolated electrically from each other. That is, the phase windings of the multiphase motor must be designed to be magnetically contacted but not to be electrically contacted. Although the voltage rating of each phase of the multiphase motor is only $1 / k$ of the input grid voltage, the insulation should be designed carefully as different stator windings may work at different electric potentials which depend on the position of the basic power cells their connected. For example, the insulation between the adjacent windings can be mainly considered according to the rated voltage of each phase of the multiphase motor if the related power cells belong to the same input phase $(\mathrm{A}, \mathrm{B}$, or C). However, the insulation between the windings should be designed based on the voltage level of the grid if the related power cells belong to different input phases, respectively. Of course, the insulation requirement between the windings and case should be treated as the same as that of their MV three-phase counterparts.

Another important issue concerns the common-mode voltage which is usual in power electronics converter-fed drives $[13,14]$. The common-mode voltage would appear on the multiphase motor causing premature failure of its winding insulation if not mitigated. For the custom-made multiphase motor, the solution is that the motor can be designed with enhanced insulation to withstand common-mode voltage stresses. Another solution is to use active switching methods by which the common-mode voltage can be reduced or eliminated $[15,16]$.

As analysed above, the proposed drive system can cover the main functions of the phase-shifting transformer in traditional multipulse MV drive systems: (1) harmonic cancellation provided by line-side cascaded H-bridges; (2) proper voltages for the motor fed by H-bridge inverters; (3) electrical isolation provided by the stator windings of the multiphase motor. Thus, the phase-shifting transformer can be cancelled.

\section{Control Scheme}

A reliable control system and control strategy are required for the proposed drive system. Based on the structural features of the proposed system, the control strategy can be divided into two decoupled parts: A line-side control strategy, and a motor-side control strategy. The former is for the three-phase cascaded H-bridge rectifier, and the latter is for the $3 k$-phase H-bridge inverter. The DC-link voltage balancing control is a challenge for the proposed drive system since the cascaded $\mathrm{H}$-bridge rectifier is loaded by independent H-bridge inverters. This issue will be discussed in the next section. Herein, the overall control strategy is merely depicted.

As shown in Figure 1, the line-side converter (rectifier) is a typical three-phase VSC. It aims to establish constant DC-link voltages and sinusoidal AC input currents, which is generally realized by a closed-loop control. Thus, the classical two loop control (a DC voltage outer loop and an AC current inner loop) is proposed for the rectifier, as shown in Figure 2. The average of DC-link voltages is compared with the reference $V_{d c}^{*}$. The error signal is inputted to the PI regulator to generate the reference $i_{d}^{*}$ for the inner control loop. In addition, the individual DC-link voltages are compared with the average to generate additional phase-shifts $\left(\Delta \alpha_{x}\right)$ through a PI regulator to correct the delay angles $(\alpha)$, which can balance the individual DC-link voltage more. A decoupled state-feedback control technique in direct-quadrature $(\mathrm{d}-\mathrm{q})$ synchronous reference frame is adopted in the AC current loop. The mathematical expression of this control strategy is shown as [22]:

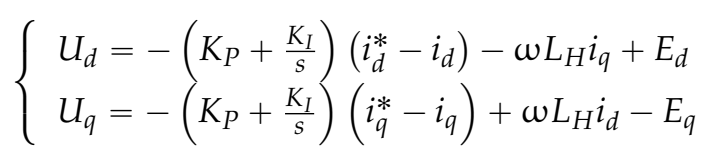

where $E_{d}$ and $E_{q}$ are the source voltages, $i_{d}$ and $i_{q}$ are the line currents, $U_{d}$ and $U_{q}$ are the AC terminal voltages of the rectifier, $\omega$ is the synchronous angular velocity, $L_{H}$ is the line inductance, $K_{p}$ is the 
proportional gain, and $K_{I}$ is the integral gain. $i_{d}^{*}$ is the reference of the active power component of the line current, which is derived from the dc voltage control loop. $i_{q}^{*}$ is the reference of the reactive power component of the line current. Here, $i_{q}^{*}$ is set to zero to maintain unity power factor on the grid side.

The DC-link voltages can be maintained at the desired reference value and the input AC currents can be controlled to be symmetrical and sinusoidal with the control strategy depicted above. For the motor-side inverters, various control schemes, such as volts-per-hertz $(\mathrm{V} / \mathrm{f})$ control, field-oriented control (FOC), direct torque control (DTC), can be adopted. For simplicity, the conventional V/f control is used in this paper. The overall control diagram is illustrated in Figure 2.

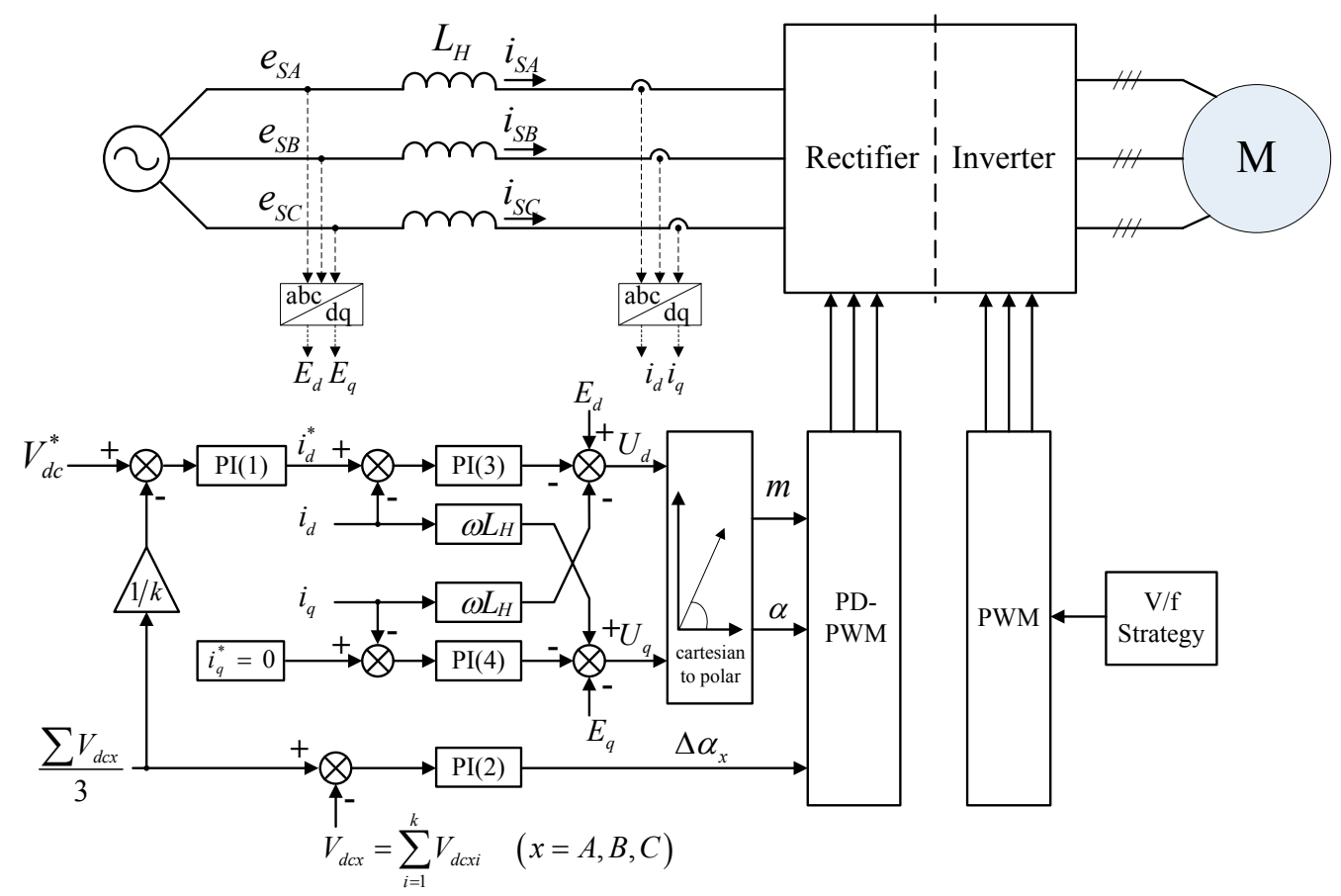

Figure 2. Control block diagram of the proposed multiphase motor drive system.

\section{DC-Link Voltage Balancing Strategy}

For the separate DC-link converter topology, like the cascaded multilevel converter used in the proposed drive system, it is a problem to ensure that individual DC-link voltages for each power cell are always balanced, which is very important to limit voltage and current stresses on the power cells and to ensure controllability. Moreover, the problem will become severe if the loads are not balanced. Some researchers have discussed the related topics. In [23], Selective Harmonic Elimination (SHE) is introduced to solve this problem, but it is only for the case in which the switching frequency is very low. A passivity-based controller for DC-link voltage balancing is designed in [24]; nevertheless, the algorithm is very complicated. In [25], several PI regulator-based DC-link voltage balancing solutions for the single-phase H-bridge multilevel active rectifier are summarized, while a huge number of PI regulators are needed when more H-bridges are cascaded. In [26], a phase-disposition PWM (PD-PWM) method for DC-link voltage balancing in the two-cell cascaded H-bridge rectifier is introduced, however, how to generalize it for three or more cells case is unclear and the details of the realization are not presented. In this paper, an improved PD-PWM method is proposed and is implemented with the help of a digital signal processor (DSP).

\subsection{Voltage Balancing Scheme Using Improved PD-PWM}

The PD-PWM is based on position shifts between carriers. Each carrier is associated with the specified voltage level. The corresponding voltage level is generated when the modulating wave is 
over its carrier wave. Therefore, if the PD-PWM is used in cascaded H-bridge converters, the H-bridge cell works only when the corresponding voltage level is reached, which produces an uneven power distribution between cells to cause the unbalanced DC-link voltages. However, this inherent uneven power distribution characteristic of the PD-PWM can be used for the proposed drive system to relieve the DC-link voltage unbalancing stresses caused by unbalanced loads (e.g., some stator windings failure of the multiphase motor). The principle is to match the uneven power distribution caused by the PD-PWM and those caused by the unbalanced loads, which is realized by regulating the charging or discharging times of the DC-link capacitors via modifying the PD-PWM. In this case, we call it improved PD-PWM.

This depends on the differences between the DC-link voltages and the direction of AC currents to control the charging or discharging times of the DC-link capacitors. For the convenience of discussion, two-cell H-bridge cascaded rectifier, as shown in Figure 3, is used to explain the operating principle of the improved PD-PWM in this section. The detailed implementation for a cascaded converter implementing more than two cells will be presented in the next section.

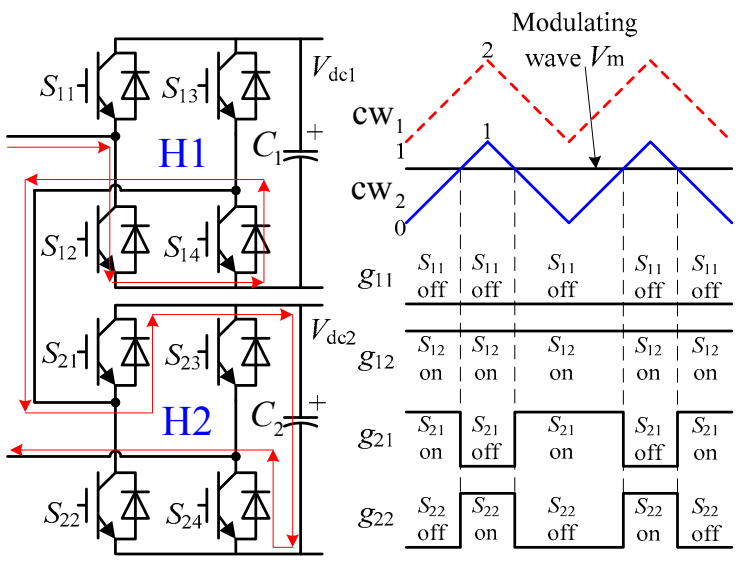

(a)

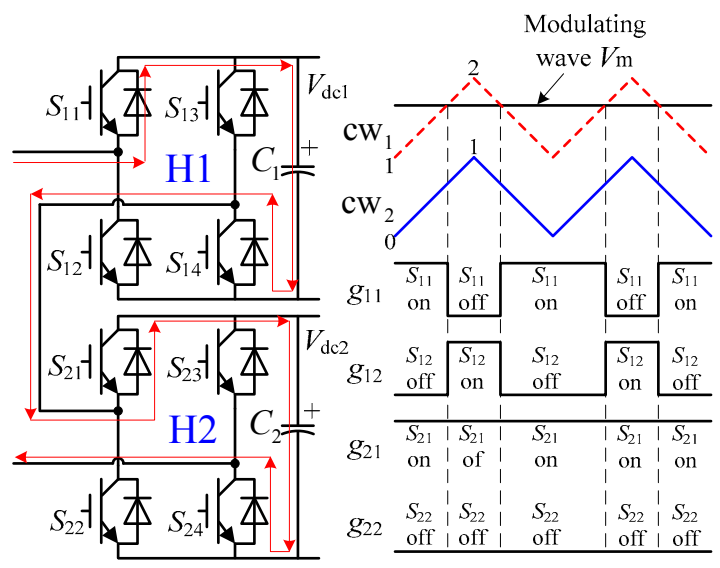

(b)

Figure 3. Principle of improved PD-PWM for DC-link voltage balancing of cascaded H-bridge rectifiers $\left(I_{\text {dir }}>0\right)$. (a) Modulating wave during [0, 1]; (b) Modulating wave during [1, 2].

Considering the modulating wave in the positive half-cycle, keep switches $S_{13}$ and $S_{23}$ off, and switches $S_{14}$ and $S_{24}$ on. Assuming that the DC capacitor voltage $V_{d c 1}$ is greater than $V_{d c 2}$, the principle of operation is as follows:

The carrier wave $\mathrm{cw}_{2}$ for the second $\mathrm{H}$-bridge $(\mathrm{H} 2)$ is placed beneath the carrier wave $\mathrm{cw}_{1}$ for the first $\mathrm{H}$-bridge $(\mathrm{H} 1)$ when the direction of the input $\mathrm{AC}$ current is from the AC source to the converter (positive, $I_{d i r}>0$ ). Then, the switching modes of $S_{11}, S_{12}, S_{21}$, and $S_{22}$ are as shown in Figure 3. The charging times for the DC capacitor $C_{1}$ and $C_{2}$ in a switching cycle are

$$
\left\{\begin{array}{l}
T_{\text {C1. charging }}=0 \\
T_{\text {C2. charging }}=V_{m} T_{S}
\end{array}, 0 \leqslant V_{m} \leqslant 1\right.
$$

or

$$
\left\{\begin{array}{l}
T_{C 1 \text {.charging }}=\left(V_{m}-1\right) T_{S}, 1<V_{m} \leqslant 2 \\
T_{C 2 \text {.charging }}=T_{S}
\end{array}\right.
$$

where $T_{C 1 \text {.charing }}$ and $T_{\mathrm{C} 2 \text {.charing }}$ are the charging times for $C_{1}$ and $C_{2}$, respectively. $V_{m}$ is the instantaneous value of the modulating wave. $T_{\mathrm{S}}$ is the switching cycle.

As can be seen from Equation (6), the charging process of the capacitor $C_{2}$ is longer than that of the capacitor $C_{1}$, which means that the capacitor $C_{2}$ obtains much more active power than the capacitor 
$C_{1}$ during that time interval, and the DC voltage $V_{\mathrm{dc} 2}$ increases relatively more than $V_{\mathrm{dc} 1}$. Therefore, the DS-link voltages $V_{d c 1}$ and $V_{d c 2}$ become equal slowly.

When the direction of the input AC current is negative $\left(I_{d i r}<0\right)$, as shown in Figure 4, the carrier wave $\mathrm{Cw}_{2}$ is placed upon the carrier wave $\mathrm{cw}_{1}$. The discharging times for the DC bus capacitors $C_{1}$ and $C_{2}$ in a switching cycle are:

$$
\left\{\begin{array}{l}
T_{C 1 \text {.discharging }}=V_{m} T_{S} \\
T_{\text {C2.discharging }}=0
\end{array}, 0 \leqslant V_{m} \leqslant 1\right.
$$

or

$$
\left\{\begin{array}{l}
T_{\text {C1.discharging }}=T_{S} \\
T_{C 2 \text { discharging }}=\left(V_{m}-1\right) T_{S}, 1<V_{m} \leqslant 2
\end{array}\right.
$$

where $T_{\mathrm{C} 1 \text {.discharing }}$ and $T_{\mathrm{C} 2 \text {.discharing }}$ are the discharging times for $C_{1}$ and $C_{2}$, respectively.

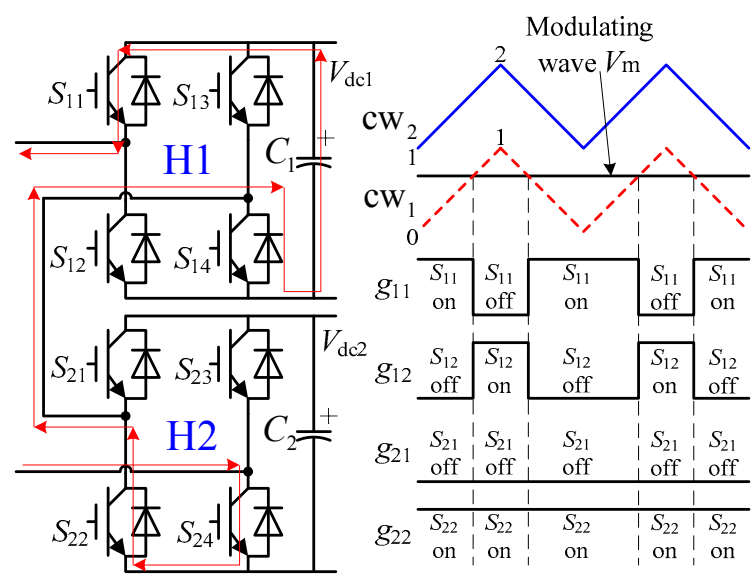

(a)

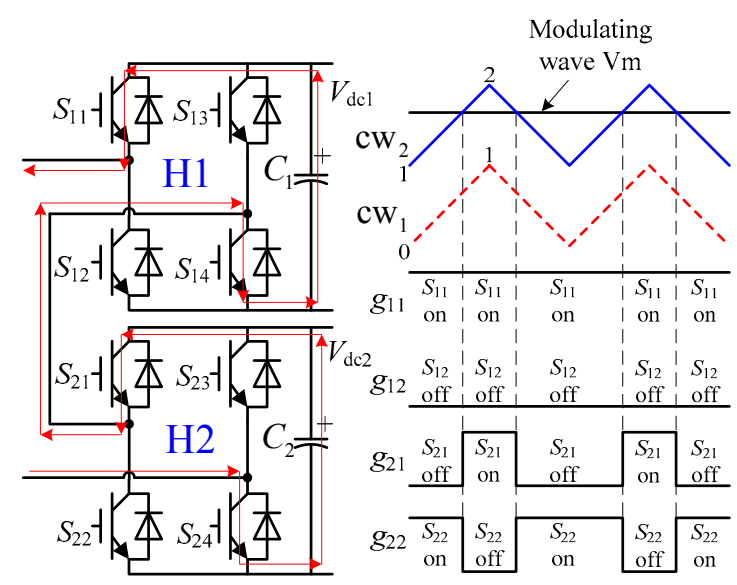

(b)

Figure 4. Principle of improved PD-PWM for DC-link voltage balancing of cascaded H-bridge rectifiers $\left(I_{d i r}<0\right)$. (a) Modulating wave during [0, 1]; (b) Modulating wave during [1, 2].

Obviously, the discharging process of the capacitor $C_{2}$ is shorter than that of the capacitor $C_{1}$, which means that the capacitor $C_{2}$ releases fewer active power than the capacitor $C_{1}$, and the DC voltage $V_{\mathrm{dc} 2}$ decreases relatively less than $V_{\mathrm{dc} 1}$. Therefore, the DC-link voltages $V_{d c 1}$ and $V_{d c 2}$ become equal.

Similarly, the modulation principle can also be drawn out in the negative half-cycle of the modulating wave. As a result, the DC-link voltage balancing control in the line-side cascaded H-bridge rectifier of the proposed drive system can be achieved by adjusting the relative position of carrier waves repeatedly in accordance with the direction of AC currents. Tables 1 and 2 present the complete modulation strategy. The proposed modulation method is not only suitable for a two-cell cascaded H-bridge converter, but also suitable for a three, or more, cell cascaded H-bridge converter.

Table 1. Modulation strategy of improved PD-PWM if $V_{d c 1}>V_{d c 2}$.

\begin{tabular}{ccccc}
\hline Direction of Current & $\begin{array}{c}\text { Positive } \\
\left(I_{\text {dir }}>\mathbf{0}\right)\end{array}$ & $\begin{array}{c}\text { Negative } \\
\left(I_{d i r}<0\right)\end{array}$ & $\begin{array}{c}\text { Positive } \\
\left(I_{d i r}>0\right)\end{array}$ & $\begin{array}{c}\text { Negative } \\
\left(I_{d i r}<0\right)\end{array}$ \\
\hline Polarity of modulating wave & positive cycle & positive cycle & negative cycle & negative cycle \\
\hline Relative position of carrier wave & $\mathrm{cw}_{1}$ upon $\mathrm{cw}_{2}$ & $\mathrm{cw}_{2}$ upon $\mathrm{cw}_{1}$ & $\mathrm{cw}_{2}$ upon $\mathrm{cw}_{1}$ & $\mathrm{cw}_{1} \mathrm{upon}_{\mathrm{cw}}$ \\
\hline
\end{tabular}


Table 2. Modulation strategy of improved PD-PWM if $V_{d c 1}<V_{d c 2}$.

\begin{tabular}{ccccc}
\hline Direction of Current & $\begin{array}{c}\text { Positive } \\
\left(\boldsymbol{I}_{\text {dir }}>\mathbf{0}\right)\end{array}$ & $\begin{array}{c}\text { Negative } \\
\left(\boldsymbol{I}_{\text {dir }}<\mathbf{0 )}\right.\end{array}$ & $\begin{array}{c}\text { Positive } \\
\left(\boldsymbol{I}_{\text {dir }}>\mathbf{0}\right)\end{array}$ & $\begin{array}{c}\text { Negative } \\
\left(\boldsymbol{I}_{\text {dir }}<\mathbf{0}\right)\end{array}$ \\
\hline Polarity of modulating wave & positive cycle & positive cycle & negative cycle & negative cycle \\
\hline Relative position of carrier wave & $\mathrm{cw}_{2}$ upon $\mathrm{cw}_{1}$ & $\mathrm{cw}_{1}$ upon $\mathrm{cw}_{2}$ & $\mathrm{cw}_{2}$ upon $\mathrm{cw}_{1}$ & $\mathrm{cw}_{2} \mathrm{upon}_{\mathrm{cw}}$ \\
\hline
\end{tabular}

\subsection{Implementation of Improved PD-PWM in DSP}

As analyzed above, the key to realizing the improved PD-PWM is to adjust the relative positions of the carrier waves for each power cell according to the magnitude of the DC-link voltages and the direction of input AC currents. Thus, the relative magnitude of the DC-link voltages should be known firstly. The flowchart of the DC-link voltage sorting function is depicted in Figure 5. The DC-link voltage values are stored in the array $V_{\mathrm{dc}}[k]$ after being sampled and calculated through AD units. Then, the relative magnitude sequence of the DC-link voltages has been stored in the array $H N O[k]$. For example, if $V_{d c 3}<V_{d c 2}<V_{d c 1}, H N O[k]$ will be equal to [2, 1, 0]; and if $V_{d c 1}<V_{d c 3}<V_{d c 2}, H N O[k]$ will be equal to $[0,2,1]$. That is the higher the voltage is, the greater the number of the array HNO[k] member corresponding to the voltage.

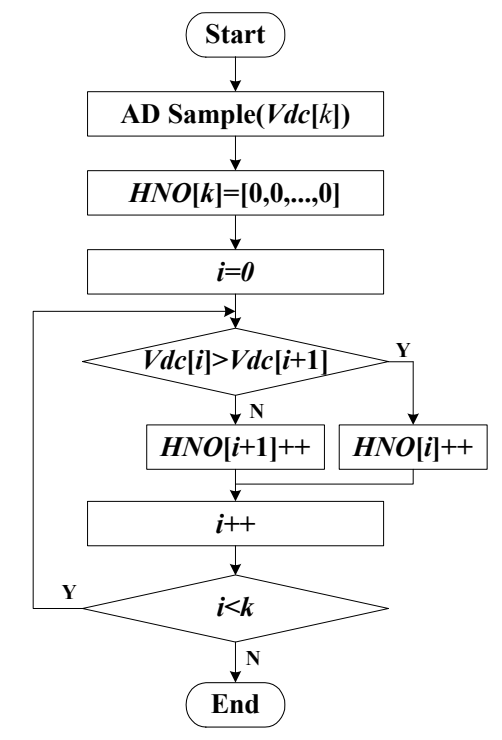

Figure 5. Flowchart of sorting DC voltage function in DSP.

The flowchart of implementation of the improved PD-PWM in DSP is shown in Figure 6. The direction of the ac current $I_{\text {dir }}$ is detected by a comparator with Schmitt-trigger characteristics.

Unlike analog PMW generator, the modulating wave is fabricated by an up-down counter in DSP and the counter value cannot be negative. Thus, it should be converted to positive when the modulating wave is in the negative half-cycle. In accordance with the symmetric PWM sampling theory, the value of time-base period (TBPRD) register for the PWM period counter in DSP is

$$
P R=\frac{f_{C L K}}{2 f_{s}}
$$

where $f_{C L K}$ is the PWM counter frequency, $f_{S}$ is the carrier wave frequency. 


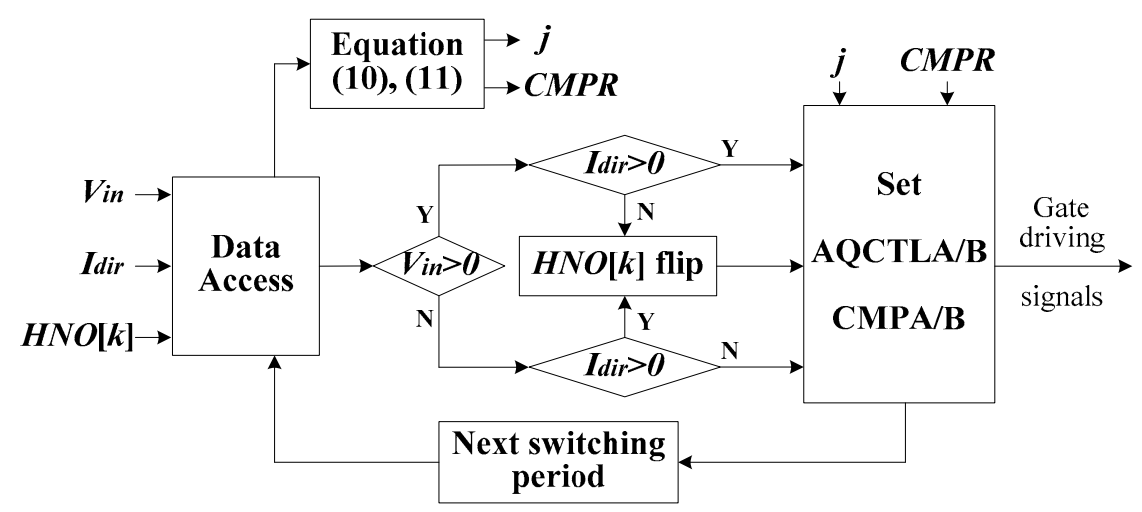

Figure 6. Implementation of improved PD-PWM in DSP.

When the improved PD-PWM works, only one H-bridge cell is under PWM control in any carrier wave cycle and the gate driving signals for switches in other $\mathrm{H}$-bridge cells are at a constant high or low level. Assuming that the sinusoidal modulation signal is $V_{\text {in }}\left(-1 \leqslant V_{\text {in }} \leqslant 1\right)$, there is:

$$
j=\text { floor }\left(k\left|V_{i n}\right|\right)
$$

where "floor" is a rounding function, and $j$ represents the position of carrier waves which should be modulated. Considering $k=3$ as an example, when $j=0$, the H-bridge cell corresponding to the lowest position of carrier wave is under pulse width modulation; and when $j=2$, the H-bridge corresponding to the highest position of carrier wave is under modulation.

The corresponding value of compare register CMPR for PWM is:

$$
C M P R=k\left|V_{i n}\right| \times P R-j \times P R
$$

As stated earlier, the data stored in the array $H N O[k]$ represent the relative magnitude of the DC-link voltages of the H-bridges. Similarly, the conditions of $V_{\text {in }}>0$ and $I_{d i r}>0$, or $V_{\text {in }}<0$ and $I_{d i r}<0$, also indicate the relative positions of the corresponding to carrier waves. Both of them should match to generate the correct PWM signals. For example, in such a case that $V_{d c 1}<V_{d c 3}<V_{d c 2}$, the array $H N O[k]$ is equal to $[0,2,1]$, that is the carrier wave for the first $\mathrm{H}$-bridge cell is placed at the bottom, and the carrier for the third H-bridge cell is in the middle position of other two carriers. However, at this moment, if $V_{\text {in }}>0$ and $I_{d i r}>0$, or $V_{\text {in }}<0$ and $I_{d i r}<0$, the data sequence stored in the array HNO[k] is opposite to the required position of the carrier waves. Thus, the value in the array $H N O[k]$ should be flipped and rearranged.

Finally, the PWM modules corresponding to the H-bridge cells in DSP should be set according to the data in the array $H N O[k]$; then the required driving signals could be generated. The driving signals with fixed level (high or low) for switches in those H-bridge cells which are not in modulation could be acquired by configuring the Action-Qualifier Output A/B Control Register (AQCTLA/B) in the DSP.

\section{Experimental Results}

The validity of the proposed drive system is verified using the experimental results of the laboratory scale prototype. The prototype includes a nine-phase motor and its drive converter with nine power cells. The drive converter is constructed using IGBT-based intelligent power modules (IPMs) (Mitsubishi Electric Corp., Tokyo, Japan) and the related controller is implemented by DSP (TMS320F2812) (Texas Instruments Inc., Dallas, TX, USA). The developed nine-phase motor and the experimental platform are shown in Figure 7. The input of the drive system is three-phase, and the nominal input AC line-to-line voltage is $380 \mathrm{~V}$. The rated power is $10 \mathrm{~kW}$. Other principal parameters of the prototype are given in Table 3. 


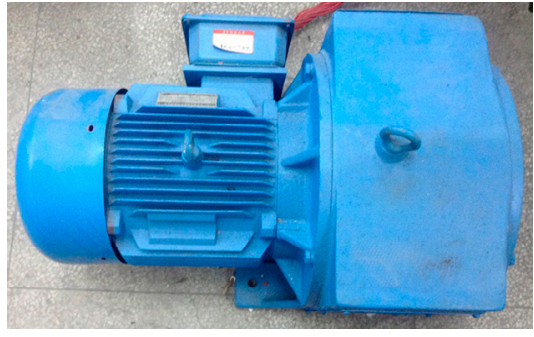

(a)

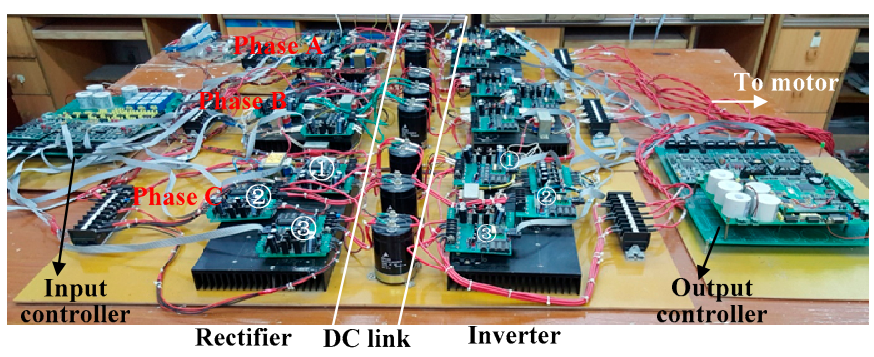

(b)

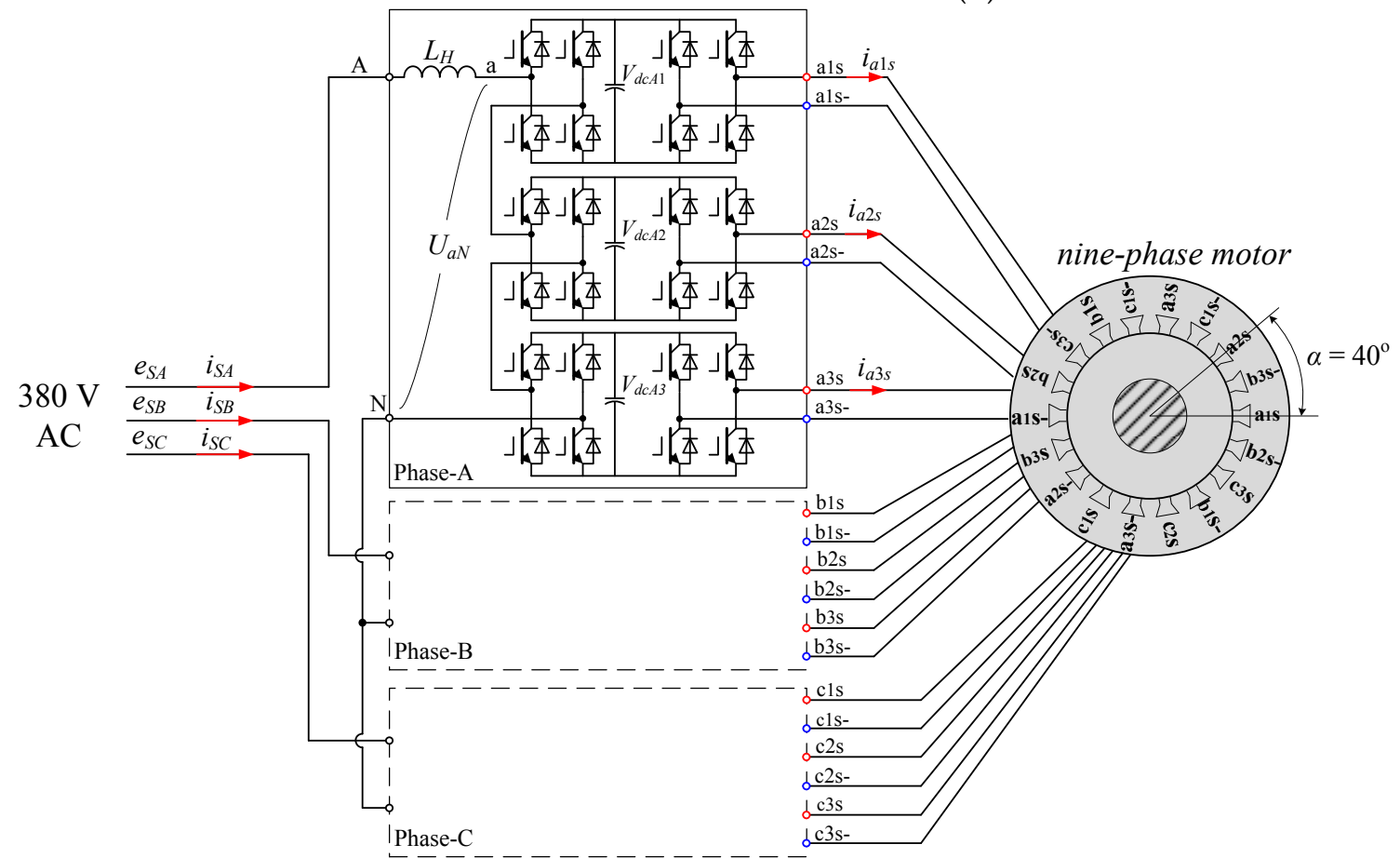

(c)

Figure 7. Experimental platform for nine-phase motor. (a) Nine-phase motor; (b) Prototype of the motor drive system; (c) Detailed test circuit.

Table 3. System parameters in the prototype.

\begin{tabular}{cc}
\hline Parameter & Value \\
\hline Number of stator windings of multiphase motor & 9 \\
Number of basic power cells (total) & 9 (3 per phase) \\
Rated power & $10 \mathrm{~kW}$ \\
Input line-to-line voltage & $380 \mathrm{~V}$ \\
DC-link voltage & $120 \mathrm{~V}$ \\
Switching frequency & $1 \mathrm{kHz}$ \\
DC bus capacitance (each DC link) & $1 \mathrm{mF}$ \\
Input line inductance $\left(L_{H}\right)$ & $3 \mathrm{mH}$ \\
\hline
\end{tabular}

The first experiment investigates the steady-state performances of the proposed drive system. Figures 8 and 9 show the related waveforms. In Figure 8, all phase currents of the stator are shown. The peak values of all stator currents are equal to about $10 \mathrm{~A}$. The phase difference between adjacent stator windings is $20^{\circ}$ because the nine stator windings of the motor are independent and uniformly distributed. 


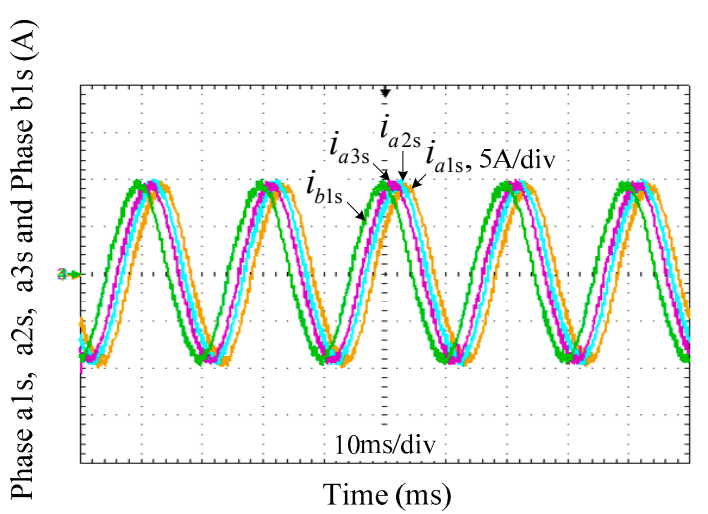

(a)

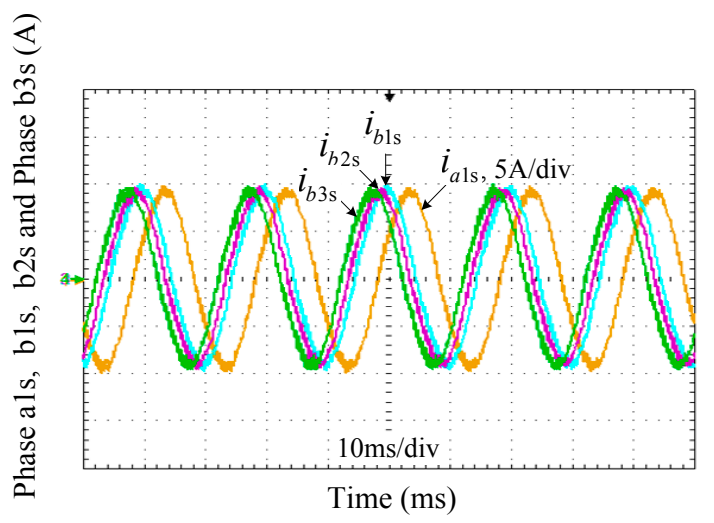

(b)

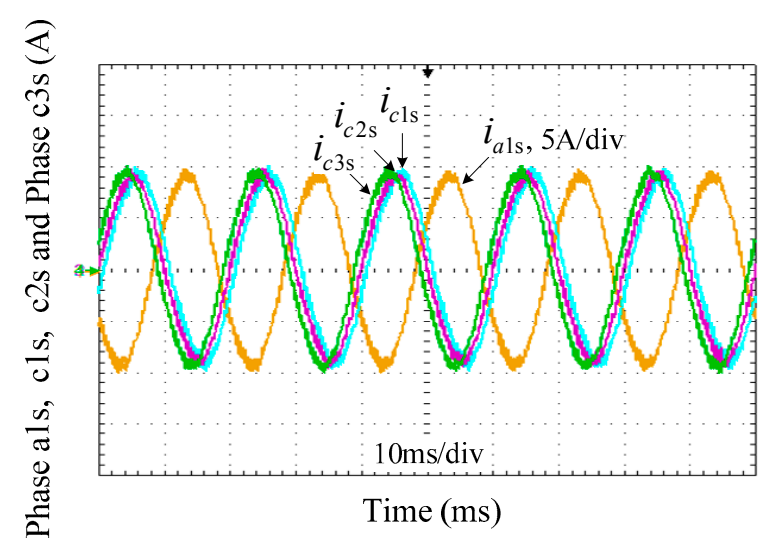

(c)

Figure 8. Stator winding currents of the motor in the steady-state. (a) Phases a1s, a2s, a3s, and b1s; (b) Phases a1s, b1s, b2s, and b3s; (c) Phases a1s, c1s, c2s, and c3s.

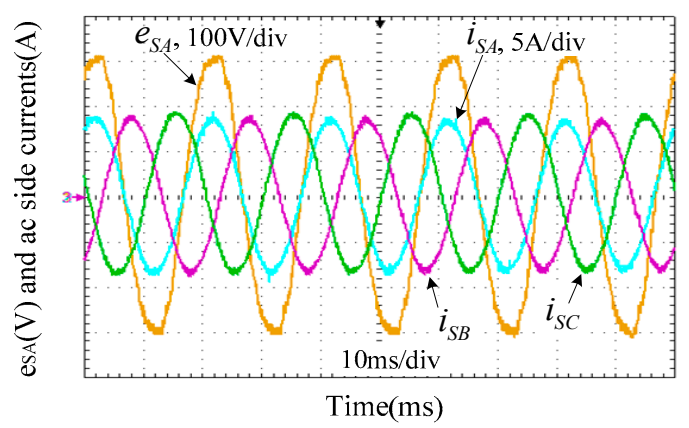

(a)

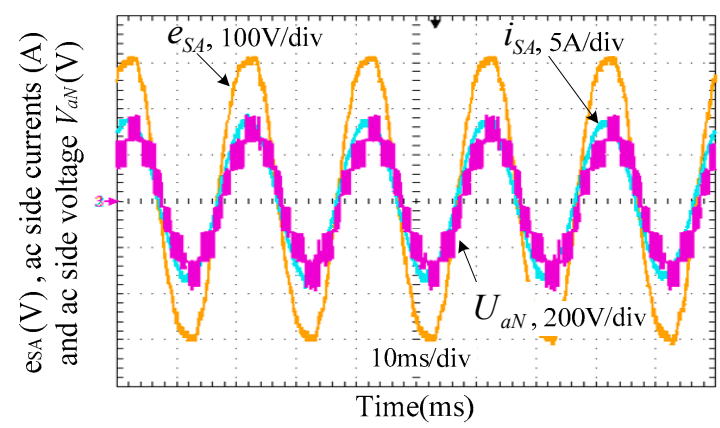

(b)

Figure 9. Voltages and currents of the drive converter in the steady-state. (a) Input voltage and currents; (b) Input voltage and current, and AC terminal phase voltage of phase A.

The steady-state voltage and current waveforms of the drive converter are shown in Figure 9. Figure 9a shows the line-side AC input voltage and currents. Although the input voltage $e_{S A}$ is slightly distorted, which caused by the leakage inductance of the autotransformer, the three-phase input currents are virtually sinusoidal. Figure $9 \mathrm{~b}$ shows the line-side AC terminal phase voltage $U_{a N}$ of the converter. There are seven levels in the phase voltage which meets the law of the cascaded H-bridge converter output voltage control.

Figure 10 depicts the DC-link voltages of the phase A under different modulation conditions. As shown in Figure 10a, the DC-link voltages have obvious imbalances among the three DC capacitors 
before the improved PD-PWM is carried out. Once the proposed improved PD-PWM for DC-link voltage balancing is implemented, the three DC-link voltages maintain a satisfying consistency, as shown in Figure 10b.

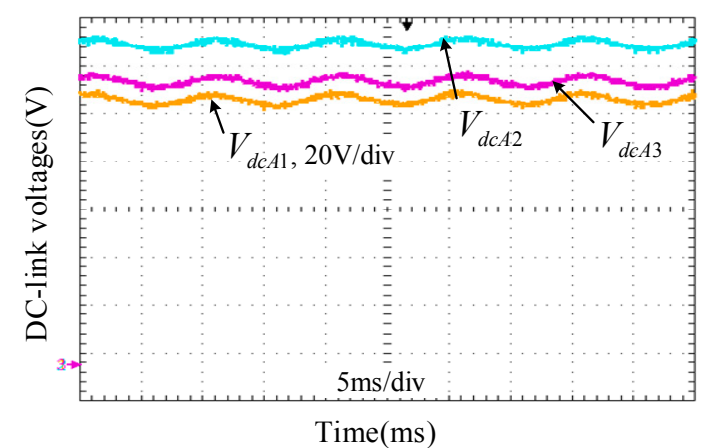

(a)

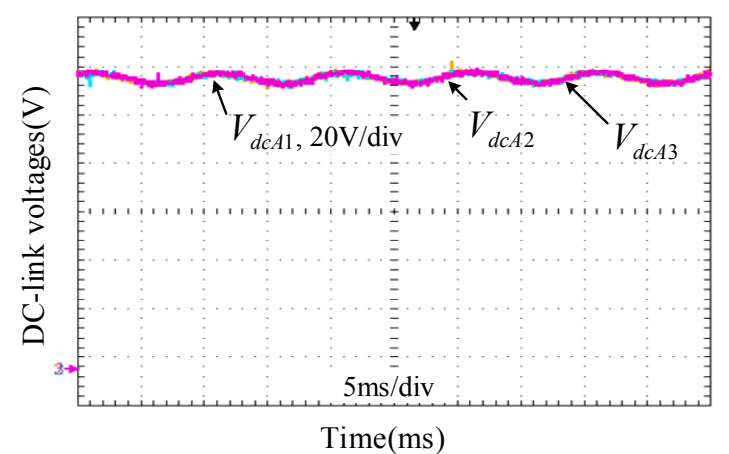

(b)

Figure 10. DC-link voltages of phase A. (a) Without the proposed DC-link voltage balancing method; (b) With the proposed DC-link voltage balancing method.

Figure 11 shows the waveforms when the multiphase motor starts at variant frequencies without mechanical load. The initial frequency of the startup is $5 \mathrm{~Hz}$. The stator winding current waveforms under different frequencies during the startup process are depicted. As shown, during the startup process, the frequency of the stator currents of the motor varies slowly as desired. The magnitudes of these currents vary slightly during the entire startup process due to no load. The entire startup process is smooth. There are harmonics in the currents at low frequencies. The reason is that the modulation indexes of the inverters are quite small at low frequency since the $V / f$ control is used.

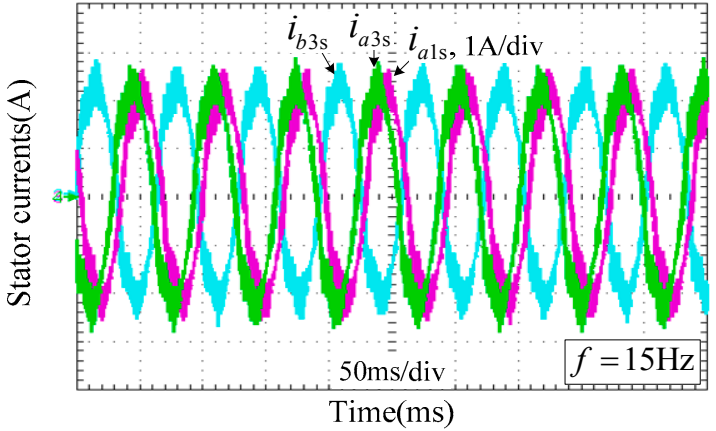

(a)

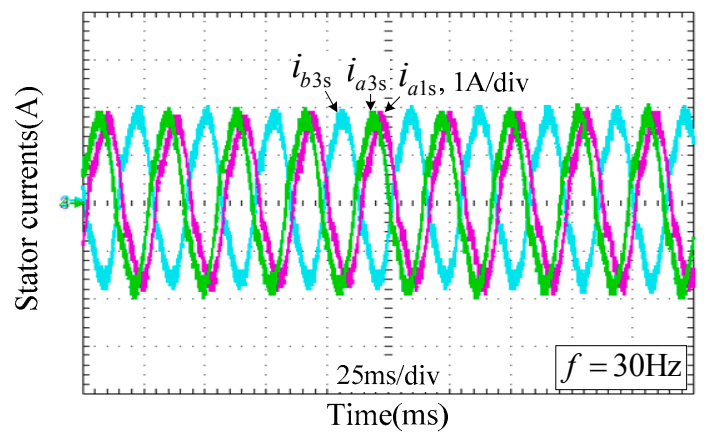

(c)

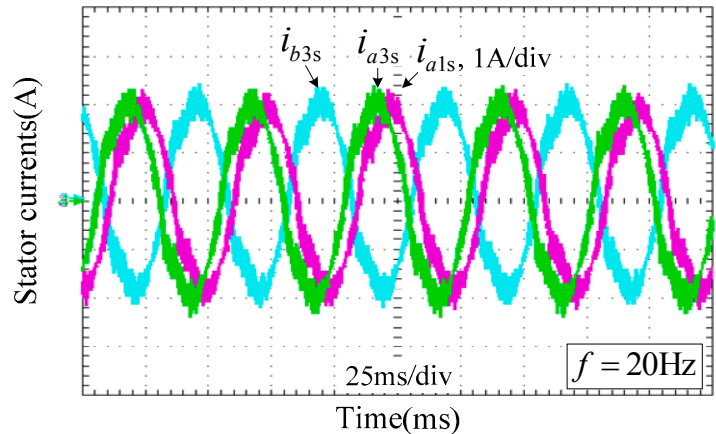

(b)

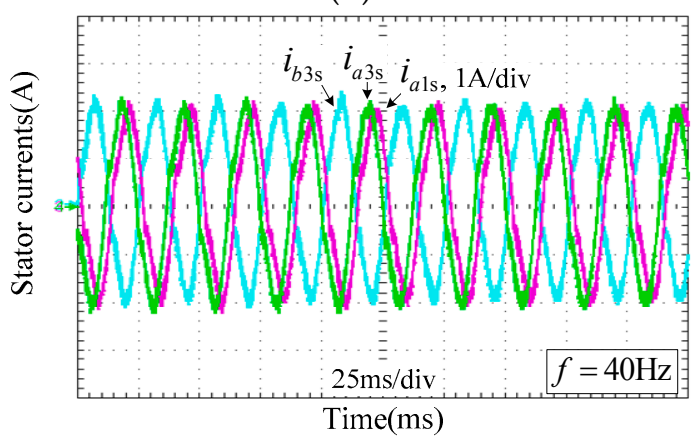

(d)

Figure 11. Stator currents during motor startup process. (a) At $15 \mathrm{~Hz}$; (b) at $20 \mathrm{~Hz}$; (c) at $30 \mathrm{~Hz}$; and (d) at $40 \mathrm{~Hz}$. 


\section{Conclusions}

Multiphase motors have high reliability and efficiency. It is expected that multiphase motor drive systems will be used widely in high-power MV and HV applications in the future. In this paper, a MV multiphase motor drive system is proposed. The drive system consists of a multiphase motor and a three-phase-input, multiphase-output static drive converter. The static drive converter is realized by multiple identical basic power cells which provide advantages with respect to implementation, maintenance, and scalability. Compared with conventional MV drive systems, the proposed drive system replaces diode rectifiers by cascaded $\mathrm{H}$-bridge converters working as active rectifiers at the input side. As a result, the traditional phase-shifting transformer is abandoned which brings the reduction of system size and cost in a great range because the traditional phase-shifting transformer takes half of the cost. The steady-state and dynamic experiments have been done to evaluate the validity of the proposed drive system and its control scheme on the laboratory-scale prototype.

Acknowledgments: This work was supported by the National Basic Research Program of China (2015CB251301, 2015CB251302).

Author Contributions: Dan Wang, Chengxiong Mao and Jiming Lu conceived the scheme; Jiawei Yang and Zhu Chen designed and performed the experiments; Dan Wang, Jiawei Yang and Zhu Chen wrote the paper.

Conflicts of Interest: The authors declare no conflict of interest.

\section{References}

1. Levi, E.; Bojoi, R.; Profumo, F.; Toliyat, H.A.; Williamson, S. Multiphase induction motor drives-A technology status review. IET Electr. Power Appl. 2007, 1, 489-516. [CrossRef]

2. Levi, E. Multiphase electric machines for variable-speed applications. IEEE Trans. Ind. Electron. 2008, 55, 1893-1909. [CrossRef]

3. Singh, G.K. Multi-phase induction machine drive research-A survey. Electron. Power Syst. Res. 2002, 61, 139-147. [CrossRef]

4. Zhao, Y.; Lipo, T.A. Space vector PWM control of dual three-phase induction machine using vector space decomposition. IEEE Trans. Ind. Appl. 1995, 31, 1100-1109. [CrossRef]

5. Toliyat, H.A.; Xu, H. A novel direct torque control (DTC) method for five-phase induction machines. In Proceedings of the Annual Conference IEEE on Applied Power Electronics Conference and Exposition, New Orleans, LA, USA, 6-10 February 2000; pp. 162-168.

6. Singh, G.K.; Pant, Y.; Singh, Y.P. Voltage source inverter driven multi-phase induction machine. Comput. Electr. Eng. 2003, 29, 812-834. [CrossRef]

7. Ryu, H.M.; Kim, J.H.; Sul, S.K. Analysis of multiphase space vector pulse-width modulation based on multiple d-q spaces concept. IEEE Trans. Power Electron. 2005, 20, 1364-1374. [CrossRef]

8. Hill, W.A.; Harbourt, C.D. Performance of medium voltage multi-level inverters. In Proceedings of the Thirty-Fourth IAS Annual Meeting, Conference Record of the 1999 IEEE Industry Applications Conference, Phoenix, AZ, USA, 3-7 October 1999; Volume 2, pp. 1186-1192.

9. Gritter, D.; Kalsi, S.S.; Henderson, N. Variable speed electric drive options for electric ships. In Proceedings of the IEEE Electric Ship Technologies Symposium, Philadelphia, PA, USA, 25-27 July 2005; pp. 347-354.

10. Krug, D.; Bernet, S.; Fazel, S.S.; Jalili, K.; Malinowski, M. Comparison of 2.3-kV medium-voltage multilevel converters for industrial medium-voltage drives. IEEE Trans. Ind. Electron. 2007, 54, 2979-2992.

11. Rodriguez, J.; Bernet, S.; Wu, B.; Pontt, J.O.; Kouro, S. Multilevel voltage-source-converter topologies for industrial medium-voltage drives. IEEE Trans. Ind. Electron. 2007, 54, 2930-2945. [CrossRef]

12. Du, Z.; Tolbert, L.M.; Chiasson, J.N.; Ozpineci, B.; Li, H.; Huang, A.Q. Hybrid cascaded H-bridges multilevel motor drive control for electric vehicles. In Proceedings of the 37th IEEE Power Electronics Specialists Conference, Jeju, Korea, 18-22 June 2006; pp. 1-6.

13. Mao, C.; Li, W.; Lu, J.; Fan, S. Study of the common-mode voltage in high-voltage ASD's system. Proc. Chin. Soc. Electr. Eng. 2003, 23, 57-62.

14. Wu, B. High-Power Converters and AC Drives; Wiley-IEEE Press: New York, NY, USA, 2006. 
15. Wei, S.; Zargari, N.; Wu, B.; Rizzo, S. Comparison and mitigation of common-mode voltage in power converter topologies. In Proceedings of the 39th IAS Annual Meeting, Conference Record of the 2004 IEEE Industry Applications Conference, Seattle, WA, USA, 3-7 October 2004; pp. 1852-1857.

16. Ahmed, S.M.; Salam, Z.; Abu-Rub, H. Common-mode voltage elimination in a three-to-seven phase dual matrix converter feeding a seven phase open-end induction motor drive. In Proceedings of the 2014 IEEE Conference on Energy Conversion (CENCON), Johor Bahru, Malaysia, 13-14 October 2014; pp. 207-212.

17. Rao, J.Y.; Li, Y. Sensor-less drive of induction motor based on a new hybrid cascaded multilevel inverter. In Proceedings of the Twenty-Fourth Annual IEEE Applied Power Electronics Conference and Exposition, Washington, DC, USA, 15-19 February 2009; pp. 1819-1823.

18. Akagi, H.; Ryota, K. A transformerless hybrid active filter using a three-level pulsewidth modulation (PWM) converter for a medium-voltage motor drive. IEEE Trans. Power Electron. 2010, 25, 1365-1374. [CrossRef]

19. Tao, X.; Xu, L.; Song, Y.; Sun, M. A transformerless cascaded AC-DC-AC converter for multiphase propulsion drive application. In Proceedings of the 2011 International Conference on Electrical Machines and Systems, Beijing, China, 20-23 August 2011; pp. 1-5.

20. Wang, K.; Zheng, Z.D.; Li, Y.D. A novel transformerless cascaded multilevel converter topology. Trans. China Electrotech. Soc. 2011, 26, 1-6. [CrossRef]

21. Li, Y.D.; Rao, J.Y. The development of high performance high power multilevel converters. Electr. Eng. 2008, 9, 7-12.

22. Ye, Y.; Kazerani, M.; Quintana, V.H. A novel modeling and control method for three-phase PWM converters. In Proceedings of the IEEE 32nd Annual Power Electronics Specialists Conference (PESC), Vancouver, BC, USA, 17-21 June 2001; pp. 102-107.

23. Watson, A.J.; Wheeler, P.W.; Clare, J.C. A complete harmonic elimination approach to DC link voltage balancing for a cascaded multilevel rectifier. IEEE Trans. Ind. Electron. 2007, 54, 2946-2953. [CrossRef]

24. Cecati, C.; Dell'Aquila, A.; Liserre, M.; Monopoli, V.G. A passivity-based multilevel active rectifier with adaptive compensation for traction applications. IEEE Trans. Ind. Appl. 2003, 39, 1404-1413. [CrossRef]

25. Dell'Aquila, A.; Liserre, M.; Monopoli, V.G.; Rotondo, P. Overview of PI-based solutions for the control of DC Buses of a single-phase H-bridge multilevel active rectifier. IEEE Trans. Ind. Appl. 2008, 44, 857-866. [CrossRef]

26. Tao, X.; Li, Y.; Sun, M. A phase-disposition PWM method for DC voltage balance in cascaded H-bridge rectifier. In Proceedings of the International Conference on Electrical Machines and Systems, Incheon, Korea, 10-13 October 2010; pp. 243-248.

(C) 2016 by the authors; licensee MDPI, Basel, Switzerland. This article is an open access article distributed under the terms and conditions of the Creative Commons Attribution (CC-BY) license (http:/ / creativecommons.org/licenses/by/4.0/). 